\title{
Effectiveness of cognitive behavioral group therapy for depression in routine practice
}

\author{
Jens C Thimm ${ }^{1,2^{*}}$ and Liss Antonsen ${ }^{2}$
}

\begin{abstract}
Background: Previous research has shown that cognitive- behavioral group therapy (group CBT) is an effective treatment for depression. However, the effectiveness of this approach in routine care needs more research. The current study retrospectively examines the outcomes of patients who received group CBT for depression at a psychiatric outpatient clinic between 2003 and 2013.
\end{abstract}

Methods: Based on patient records, 143 patients were identified as having received the treatment, and 88 patients were included in the outcome analyses. The Beck Depression Inventory (BDI-II) score was the main outcome measure.

Results: The dropout rate was $17.5 \%$. The average BDI-II score decreased from 28.5 to 18.5 from pre-treatment to post-treatment and remained stable at 3-months follow-up. The effect sizes at post-treatment and follow-up were large $(d=.97$ and $d=1.10$, respectively). At post-treatment, $44 \%$ of the patients showed a significant improvement in depression, including 30\% who recovered; at follow-up, the proportions increased to $57 \%$ and $40 \%$, respectively. No predictors of dropout or treatment response were found.

Conclusions: Group CBT for depression can be delivered in routine care settings with good results. However, there are still many patients who drop out or do not benefit from treatment.

Keywords: Cognitive-Behavioral Group Therapy, Depression, Effectiveness, Routine Care

\section{Background}

The majority of systematic reviews and meta-analyses have concluded that cognitive behavior therapy (CBT) is an efficacious treatment for depression [1-3]. In various treatment guidelines, e.g., the NICE guideline [4], CBT is therefore recommended as the first-line treatment for depression.

Delivering CBT for depression in a group format is a cost-effective alternative to individual treatment $[5,6]$. Group therapy may provide further advantages, as patients may benefit from group cohesion and normalization effects and may also be able to use the group as an arena for engaging in behavioral experiments, learning from others and functioning as co-therapists $[7,8]$. On the other hand, group therapy is not acceptable to some patients, and there is less time allotted and less opportunity to tailor treatment to the individual patient [8].

\footnotetext{
* Correspondence: jens.thimm@uit.no

${ }^{1}$ Department of Psychology, University of Tromsø, 9037 Tromsø, Norway ${ }^{2}$ Helgeland Hospital Trust, 8607 Mo i Rana, Norway
}

A meta-analysis of 48 randomized controlled trials (RCTs) by McDermut, Miller, and Brown [9] shows that different forms of group therapy effectively reduce depressive symptoms. The authors found an overall effect size of 1.03 and that CBT was somewhat more efficacious than psychodynamic group therapy. In a review of 34 studies on group therapy for depression, Oei and Dingle [10] also examined measures of cognitions, behaviors and general health in addition to depression severity in their analyses. Based on 13 controlled studies, the authors found an average effect size of 1.11 in favor of group CBT. Analyses of 21 uncontrolled studies showed an average effect size of 1.30 for comparisons between pre-treatment and post-treatment scores. Oei and Dingle [10] concluded that group CBT for depression is as effective as other bona fide treatments as defined by Wampold, Minami, Baskin, and Callen Tierney [11]. With respect to group CBT provided in primary care or in the community, a meta-analysis of 14 randomized controlled trails by Huntley, Araya, and Salisbury [12] 
showed a significant effect of group CBT over usual care at post-treatment and medium- to long-term follow-up; the standardized mean differences (SMDs) reported by the authors were -.55 and -.47 , respectively. The authors further found that individually delivered $\mathrm{CBT}$ was superior to group $\mathrm{CBT}(\mathrm{SMD}=.38)$ immediately after treatment, but not at follow-up. Similarly, the results of the meta-analysis conducted by Cuijpers, van Straten, and Warmerdam [13] suggest that group CBT for depression might be slightly less effective than individual therapy in the short-term. A recent review by Okumura and Ichikura [14] extended previous meta-analyses in several respects by comparing group CBT for depression with different levels of treatment intensity as described in stepped care models for depression [4]. Their meta-analysis of 35 studies showed that group CBT was superior to nonactive controls $(\mathrm{SMD}=-.68)$ and that there was a small but non-significant advantage of group CBT above middle-intensity interventions $(\mathrm{SMD}=.21)$.

Concerns have been raised as to whether the findings from research studies can be generalized to routine clinical practice. In this context, it is common to distinguish between the efficacy and the effectiveness of a treatment $[15,16]$. Efficacy refers to the results achieved in research trials, whereas effectiveness is understood as the therapy outcome in routine practice. The primary goal of research trials is to establish a causal relationship between a given treatment and an outcome (internal validity). In research trials, participants are often selected patients and are treated by trained therapists who follow treatment manuals strictly, receive regular supervision and whose treatment adherence is closely monitored [15]. In contrast, routine clinical practice is characterized by unselected patients, high therapist caseloads, and flexible use of treatment protocols. It has been suggested that due to strict exclusion criteria, patients participating in clinical trials are not representative of patients typically seen in clinical practice in terms of severity and comorbidity, compromising the generalizability of RCTs (external validity) $[17-20]$. However, recent studies report only minor differences in clinical characteristics between patients participating in RCTs and patients seen in clinical practice, which may indicate more liberal inclusion criteria in more recent RCTs [21-23]. Due to practical and ethical reasons, randomization of patients to an active or non-active control condition is often not feasible in ordinary clinical settings, and some authors have argued that randomization is not representative of clinical practice [24]. Finally, due to publication bias, the effects of treatment for depression found in research trials may be overestimated [25]. Therefore, research on the effectiveness of treatment in routine clinical practice is needed. Although effectiveness studies do not typically have a control group and are therefore unable to establish causal relationships, they may provide valuable information about a given treatment.

Several studies have investigated the effectiveness of CBT for adult depression in routine practice e.g., [26,27]. Recently, Hans and Hiller [24] conducted a meta-analysis of these studies. To define the clinical representativeness of a study, the authors suggested the following criteria based on the work of Shadish and colleagues [28,29]: (a) non-university setting; (b) referred patients; (c) professional therapists with regular caseloads; (d) flexible structure; (e) no monitoring of treatment implementation; and (f) no therapist training for study purposes. A total of 34 studies (1,880 patients) were included in the analyses. Hans and Hiller [24] found an average pre-post effect size of 1.13 for treatment completers and 1.06 for intent-to-treat analysis in reducing depression severity. There were no significant differences between individual and group therapy in this regard. Effect sizes between 0.67 and 0.88 were found for secondary outcome measures (e.g., dysfunctional cognitions, anxiety). The mean dropout rate was $25 \%$ and was significantly higher in individual (on average 42\%) than group CBT (17\%). Hans and Hiller [24] concluded that outpatient individual and group therapy for depression is effective in routine clinical practice. However, the authors characterized their findings as preliminary as the number of available studies was low and samples sizes were often small.

Thus, the purpose of the present study is to add to the knowledge base about the effectiveness of treatment for depression in routine clinical practice settings. In this study, we retrospectively evaluated the effectiveness of group CBT treatment administered in a specialized psychiatric outpatient clinic; the Beck Depression Inventory (BDI) [30,31] were used to assess patients' depression severity before treatment, during treatment, after treatment, and at 3-months follow-up. In addition, the current study aimed to investigate the pattern of patient dropout from treatment and differences between patients who benefit from the treatment and those who do not respond to the intervention.

\section{Method}

\section{Participants}

The present study draws from a project that evaluated the effectiveness of a treatment for depression given at the group therapy unit at the Psychiatric Centre of the Helgeland Hospital Trust in Mo i Rana in Norway. The center is a secondary care setting located in a rural area near the polar circle that serves a population of approximately 33,000 individuals. Patients are referred to the clinic primarily by their general practitioner, but other specialized health services can also refer patients to the outpatient clinic.

Using the hospital's electronic record system, the records of patients who were registered as having received cognitive 
behavioral group therapy for depression between 2002 and 2013 were reviewed. A total of 143 patients (71\% female, mean age $=41.6$ years, range $=20$ to 69 years) were identified; the patients had participated in 26 different treatment groups. The dropout rate was $17.5 \%$ (25 patients). We defined dropouts broadly as patients who attended the first group session but discontinued the treatment at a later time point. Treatment completers could miss single sessions. For 88 patients (62\% of the total sample), $73 \%$ female with a mean age of 41.8 years $(\mathrm{SD}=11.3$, range $=20-68)$, a pre-treatment and post-treatment or follow-up scores on the BDI were available; these patients were included in the outcome analyses. Further demographic and clinical characteristics of this sample are displayed in Table 1. Until 2006, the patients' diagnoses were established using the Structured Psychiatric Interview for General Practice SPIFA; [32]. Since 2006, the MINI [33] has been routinely used for diagnoses at the group treatment unit.

\section{Therapists and treatment}

The groups were led by a therapist and co-therapist. The therapists were mainly psychiatric nurses, but other mental health professionals (e.g., psychologists) were also group leaders. During the period studied, all therapists had received formal training in CBT. Prior to treatment and baseline assessment with the BDI-II and the BAI, a member of the group therapy unit met the client for a clinical assessment (if the client had not been diagnosed before), to provide information about the group treatment, to discuss with the patient whether the treatment was suitable for him or her and to

\begin{tabular}{|c|c|}
\hline Sample characteristics & N (\%) \\
\hline Cohabitating or married & $56(63.6)$ \\
\hline \multicolumn{2}{|l|}{ Education } \\
\hline Lower secondary school & $16(18.2)$ \\
\hline Upper secondary school & $38(43.2)$ \\
\hline Higher education & $25(28.4)$ \\
\hline Unknown & $9(10.2)$ \\
\hline Working & $49(55.7)$ \\
\hline \multicolumn{2}{|l|}{ First diagnosis (ICD-10) } \\
\hline F32 Depressive episode & $26(29.5)$ \\
\hline F33 Recurrent depressive disorder & $44(50)$ \\
\hline F34.1 Dysthymia & $10(11.4)$ \\
\hline $\begin{array}{l}\text { Other (bipolar disorder (2), obsessive-compulsive } \\
\text { disorder (1), post-traumatic stress disorder (2), } \\
\text { adjustment disorder (2), avoidant personality disorder (1)) }\end{array}$ & $8(9.1)$ \\
\hline Patients with $\geq 2$ diagnoses & $28(31.8)$ \\
\hline
\end{tabular}

determine the patients' motivation. This clinical assessment period typically lasted approximately $4-5$ sessions. Group sessions were closed and comprised 5-7 patients when they started. The treatment initially consisted of 12 weekly sessions, but was later extended to 15 sessions. Each session lasted 120 minutes, including a 15-minute break. The content of the group sessions was based on manuals for the cognitive behavioral treatment of depression that were available in Norwegian [34]. As no single manual was used during the study period, there was some variation in the treatment received by groups. However, the core elements of CBT for depression, such as psychoeducation, behavioral activation, and cognitive restructuring, were central to all treatments. In its current form, the group CBT treatment given at the center is guided by the manual written by Hagen and Gråwe [34], and the elements are psychoeducation about depression (two sessions), self-assertion, interpersonal relationships, and social network (three sessions), resources and pleasurable activities (one session), the cognitive model of depression and cognitive restructuring (eight sessions), and relapse prevention and evaluation of treatment (one session). A patient workbook is used during treatment. Each session has the following structure: 1) review of homework; 2) presentation of topic A; 3) exercise related to topic A - conducted individually, in pairs, or in groups; 4) break; 5) presentation of topic B; 6) exercise related to topic $\mathrm{B}$ - conducted individually, in pairs, or in groups; and 7) presentation of homework. (A parts and timing plot detailing the current treatment timeline can be found in the online appendix). Approximately three months after the last treatment session, patients receive a follow-up group session that focuses on treatment evaluation and relapse prevention.

\section{Measures}

The BDI is the main outcome variable in the present study. The BDI [30] and its successor, the BDI-II [31], are widely used, 21-item, self-report inventories designed to assess depression severity. Items are answered on a four-point scale ranging from 0 to 3 . The BDI was used at the group therapy unit until the spring of 2009, at which point use of the BDI-II began. Due to the differences between the two versions of the inventory, all BDI scores were converted to BDI-II scores using the adjustment table in the BDI-II manual [31] for comparability. According to the BDI-II manual, the adjustment table is based on a study of psychiatric outpatients and an equipercentile equating method [31]. The Norwegian version of the BDI-II has been shown to have a high internal consistency (Cronbach's alpha $=.91$ ) and an acceptable test-retest reliability (.77) over a three week period [35].

The Beck Anxiety Inventory (BAI) [36] consists of 21 items assessing the severity of anxiety symptoms on a four-point scale ranging from 0 to 3 . The Cronbach's 
alpha for the Norwegian version of the BAI is .88 , and its test-retest reliability over three weeks is .69 [37].

The BDI/BDI-II and BAI were administered to patients at the start of group treatment, at approximately mid-treatment (week 7), at the end of the group treatment, and at 3-months follow-up (Additional file 1).

According to the Norwegian Health Research Act, approval from the Research Ethics Committee is not required for the evaluation of routine service delivery (http://www.regjeringen.no/upload/HOD/HRA/ Helseforskning/Helseforskningsloven\%20-\%20 E NG E L SK\%20endelig\%2029\%2006\%2009.pdf and http://www. regjeringen.no/upload/HOD/HRA/Veileder $\% 20$ til $\% 20$ helseforskningsloven.pdf). The Data Protection Official for Research for the Helgeland Hospital Trust was notified of the study.

\section{Statistical analyses}

Differences between subgroups of patients were investigated using $\mathrm{x} 2$ tests for categorical data and ANOVA for quantitative variables. The overall effect of the treatment was examined using multilevel modeling. This approach was considered particularly suited for the current investigation, as the analyses did not require complete data for every subject $[38,39]$. In the analyses, time was defined as fixed factor, and the BDI-II and BAI scores were the dependent variables. Group membership was defined as a level 2 variable. Random intercepts and slopes were specified. Finally, an autoregressive covariance structure with heterogeneous variances was assumed. Unfortunately, as almost no data were available for patients who dropped out of treatment, intent-to-treat analyses could not be performed. Effect sizes (d) between two time points were calculated by dividing the mean differences in outcome variables by the standard deviations of the differences. Uncontrolled effect sizes were calculated for available data pairs and for a data set in which missing data were imputed. The handling of missing data followed the recommendations of Schlomer, Bauman, and Card [40] and Sterne et al. [41]. To evaluate the pattern of missing data, Little's [42] MCAR test was used. Missing BDI-II and BAI values were imputed by means of a multiple imputation procedure [43] using the automatic method in SPSS 21.0. The number of imputations was specified as 20, and the range of imputed values was constrained to a minimum of 0 and a maximum of 63 . The automatic method uses linear regression as model for scale variables [44]. All available BDI-II and BAI scores were included in the imputation procedure.

To further evaluate treatment success and to categorize patients as recovered, improved, unchanged, or deteriorated, the Jacobson and Truax [45] approach as recommended by Bauer, Lambert, and Nielsen [46] was used. For the BDI, cut-off values for reliable change and recovery have been developed [47]. However, as a the BDI and the BDI-II are not entirely identical instruments, it was decided to calculate cut-off scores for the BDI-II and BAI based on the characteristics of the present sample and existing data from the Norwegian general population [35,37]. Patients who showed no reliable change in their BDI-II scores were classified as "unchanged". If there was a reliable change in negative direction, the patient was classified as "deteriorated". Patients showing reliable change in positive direction were classified as "improved", and if patients' BDI-II scores were below the cut-off for the normal range in addition, the patients were classified as "recovered".

\section{Results}

\section{Analysis of dropouts and representativeness of the outcome sample}

As mentioned above, 25 (17.5\%) of the 143 patients who started the treatment dropped out. For dropouts, the demographic characteristics of age and sex and the diagnosis were collected and available for analyses. The mean age of patients who dropped out was 38 years $(\mathrm{SD}=11.4)$, and 18 (72\%) were female. Patients who dropped out attended an average of 4.5 sessions $(\mathrm{SD}=2.8$ ). Age, sex, diagnosis, and pre-treatment scores of the BDI-II and BAI of treatment completers versus dropouts were compared. There was a tendency ( $p=0$.083) for dropouts to be younger than treatment completers, but no significant differences between completers versus dropouts were found with respect to sex, diagnosis, and BDI-II and BAI scores at pre-treatment. Participants dropped out for a variety of reasons, including the need for inpatient or individual treatment $(\mathrm{n}=12)$, symptom reduction $(\mathrm{n}=3)$, disagreement with the therapist $(\mathrm{n}=2)$, absence due to family problems $(\mathrm{n}=2)$, sexual harassment of a group member $(\mathrm{n}=1)$, pregnancy problems $(\mathrm{n}=1)$, somatic illness $(\mathrm{n}=1)$, meeting of an acquaintance in the group $(\mathrm{n}=1)$, and unknown $(\mathrm{n}=2)$. Fourteen of the dropout patients received an alternative treatment. Treatment completers attended an average of 12.1 session ( $\mathrm{SD}=1.7$, range $=9-15)$. Approximately one quarter of the participants (27\%) attended all sessions.

To examine the representativeness of the sample, treatment completers $(\mathrm{n}=88)$ with and without BDI-II scores available at pre-treatment and post-treatment or follow-up were compared with respect to sex, age, diagnosis, and BDI-II and BAI scores at pretreatment. No significant differences were found between treatment completers with and without BDI-II scores, indicating that the patients included in the following analyses are representative of all treatment completers.

\section{Effect of treatment}

The means, standard deviations, and percentage of missing data at the four time points are displayed in Table 2. Little's 
Table 2 Descriptive statistics for the BDI-II and the BAI at pre-treatment, mid-treatment, post-treatment, and follow-up

\begin{tabular}{|c|c|c|c|c|c|c|c|c|}
\hline & \multicolumn{2}{|l|}{ Pre-treatment } & \multicolumn{2}{|l|}{ Mid-treatment } & \multicolumn{2}{|l|}{ Post-treatment } & \multicolumn{2}{|l|}{ Follow-up } \\
\hline & $\mathrm{M}$ (SD, range) & $\begin{array}{l}\text { Number of } \\
\text { missing } \\
\text { data }(\%)\end{array}$ & M (SD, range) & $\begin{array}{l}\text { Number of } \\
\text { missing } \\
\text { data (\%) }\end{array}$ & $\mathrm{M}$ (SD, range) & $\begin{array}{l}\text { Number of } \\
\text { missing } \\
\text { data (\%) }\end{array}$ & M (SD, range) & $\begin{array}{l}\text { Number of } \\
\text { missing } \\
\text { data (\%) }\end{array}$ \\
\hline BDI-II & $28.52(10.42,2-53)$ & $0(0)$ & $23.03(11.24,0-51)$ & $15(17)$ & $18.53(11.09,1-44)$ & $18(20.5)$ & $18.26(12.24,0-53)$ & $19(21.6)$ \\
\hline BAl & $19.07(13.09,0-58)$ & $21(23.9)$ & $17.60(11.73,0-54)$ & $33(37.5)$ & $14.12(11.43,0-45)$ & $37(42)$ & $14.74(12.23,0-46)$ & $31(35.2)$ \\
\hline
\end{tabular}

MCAR test was non-significant, $\mathrm{X} 2(72)=66.56, p=.66$, supporting the assumption that data were missing at random, which is a prerequisite for multilevel modeling and multiple imputation $[38,43]$. As shown in Table 2, except for the BDI-II at pre-treatment, there were missing data at every time point, ranging from $17 \%$ (BDI-II at mid-treatment) to $42 \%$ (BAI at post-treatment). Approximately two third of cases (64.3\%) had missing data for at least one time point; in total $24.7 \%$ of the outcome values were missing. The reasons for missing data could not be determined from the electronic record system.

The average BDI-II scores decreased from 28.5 to 18.5 from pre-treatment to post-treatment and remained stable at follow-up (18.2). Mixed-level analysis showed a significant linear effect of time on depression, $F(1$, $272,98)=66.26, p<.001$. The linear effect of time on anxiety was also significant, $\mathrm{F}(1,215,58)=8.71, p<.01$. There were no differences between treatment groups. Effect sizes for the differences between the pre-treatment scores and patients' scores at the three other time points are shown in Table 3. The table contains effect sizes based on available data in addition to effect size estimations using multiple imputation of missing data. Applying Cohen's [48] criteria $(\mathrm{d}=.2$ : small effect; $\mathrm{d}=.5$ : medium effect; $d=.8$ : large effect), the effect sizes for depressive symptoms based on available data at post-treatment $(\mathrm{d}=.97)$ and follow-up $(\mathrm{d}=1.10)$ indicate a large effect, and the effect sizes for anxiety indicate a moderate effect $(\mathrm{d}=.52$ and $\mathrm{d}=.50$, respectively). There were only minor differences in effect size estimations between those based on actual data versus data including multiple imputations of missing data.

\section{Treatment response}

Application of the Jacobson and Truax [45] formula resulted in cut-off scores indicating a reliable change in symptom severity of 10 for the BDI-II and 10.88 for the BAI. Cut-off scores for the normal range of the
BDI-II and BAI were 16.66 and 9.26, respectively. The latter value for the BDI-II is slightly higher than the cut-off scores for the BDI reported by Seggar et al. [47] and others [49], which typically range from 13 to 15 . A probable explanation for the difference in the cut-off scores is that the BDI scores are, in general, somewhat higher than the BDI-II scores according to the adjustment table in the BDI-II manual. Patients scoring in the normal range of the BDI-II and BAI at pre-treatment were excluded from the analyses.

Available data on depression severity at post-treatment ( $\mathrm{n}=61$ ) showed that 2 patients $(3.3 \%)$ had deteriorated, 32 (52.5\%) remained unchanged, 9 (14.8\%) had improved, and $18(29.5 \%)$ had recovered after treatment. At followup ( $\mathrm{n}=63), 1$ patient $(1.6 \%)$ had deteriorated, 26 (41.3\%) remained unchanged, 11 (17.5\%) had improved and 25 (39.7\%) had recovered compared to treatment start. With respect to anxiety ( $\mathrm{n}=39), 1$ patient $(2.6 \%)$ had deteriorated, 26 (66.7\%) remained unchanged, 11 (28.2\%) had improved, and $1(2.6 \%)$ had recovered at posttreatment. At follow-up ( $\mathrm{n}=43), 3$ patients $(7 \%)$ had deteriorated, 28 (65.1\%) remained unchanged, 6 (14\%) had improved, and 6 (14\%) had recovered.

\section{Predictors of treatment effects}

To investigate the characteristics of treatment responders, patients who showed reliable improvement (including recovery) were compared to the group of patients who had either no significant positive change or had deteriorated at post-treatment. The two groups were compared on all available demographic and clinical characteristics (i.e., age, sex, partner status, education, working, first diagnosis, and number of diagnoses), pre-treatment scores on the BDI-II and BAI, and the number of sessions attended. There was a tendency for patients who benefited from the treatment to have higher scores on the BDI-II at pre-treatment compared to those who did not benefit (32.59 and 28.61, respectively, $p=.098)$. However, there were no significant

Table 3 Effect sizes (d)

\begin{tabular}{|c|c|c|c|c|c|c|}
\hline & \multicolumn{2}{|c|}{ Pre-treatment to mid-treatment } & \multicolumn{2}{|c|}{ Pre-treatment to post-treatment } & \multicolumn{2}{|c|}{ Pre-treatment to follow-up } \\
\hline & Available data (N) & MI of missing data & Available data $(\mathrm{N})$ & MI of missing data & Available data $(\mathrm{N})$ & MI of missing data \\
\hline BDI-II & $0.59(73)$ & 0.53 & $0.97(70)$ & 1.00 & $1.10(69)$ & 1.07 \\
\hline BAI & $0.17(54)$ & 0.16 & $0.52(51)$ & 0.49 & $0.50(54)$ & 0.43 \\
\hline
\end{tabular}

Note. $M I=$ multiple imputation. 
differences on the remaining variables examined between treatment responders and non-responders.

\section{Discussion}

The aim of the present study was to examine the effectiveness of group cognitive behavioral therapy for depression in a routine care setting and to explore predictors of treatment dropout and response. The routine care setting - a rural outpatient clinic - meets Hans and Hiller's [24] criteria for clinical representativeness.

The results showed a significant reduction in depression and anxiety among patients who received group CBT. The observed treatment gains were maintained at 3-months follow-up. The effect sizes of group CBT for depression were large $(\mathrm{d}=.97$ and $\mathrm{d}=1.10$ at post-treatment and follow-up, respectively) and were similar to the results reported in Hans and Hiller's [24] meta-analysis of the effectiveness of outpatient CBT for depression $(d=1.13)$, adding further support to their findings. In contrast, the effect of group CBT on the severity of anxiety symptoms was only moderate, suggesting that the treatment effect may be specific to depressive symptoms resulting in more positive outcomes for the targeted problem. In terms of clinical significance, the results showed that approximately $44 \%$ of the patients saw a significant improvement in depression severity at post-treatment, including approximately $30 \%$ who recovered. At follow-up, the proportion of patients who improved and recovered increased to $57 \%$ and $40 \%$, respectively. Thus, a considerable number of patients benefited from the treatment. However, effect sizes in the present study are lower than the results reported from efficacy studies. For example, Teri and Lewinsohn [50] and Neimeyer, Kazantzis, Kassler, Baker, and Fletcher [51] found effect sizes of 1.93 and 1.19 for group CBT for depression, respectively. The lower effect sizes found in this study are in accordance with previous studies showing significantly lower effect sizes for treatment of depression in routine care settings compared to research trials $[24,52]$. On the other hand, the response rates at follow-up are comparable to those found in efficacy studies or effectiveness studies conducted in university settings. According to Keitner, Ryan and Solomon [53], in efficacy studies, $50-58 \%$ of depressed patients respond to and $30-48 \%$ recover after psychotherapy. Peeters et al. [54] found a remission rate of $37 \%$ after 26 weeks of individual cognitive behavioral therapy for depression using the BDI-II to assess outcomes. Unfortunately, the cut-off values on the BDI-II used to define response and remission vary between studies, making direct comparisons difficult. For example, Peeters et al. [54] used a more conservative BDI-II cut-off score of 10 to distinguish between the normal and clinical range. In the current study, neither demographics nor pre-treatment scores on the BDI-II or BAI predicted treatment response. The finding that age and sex are unrelated to treatment outcomes has been reported previously [55], but some studies have found that older age is associated with a poorer outcomes [55]. There was a tendency $(p<.10)$ for patients with higher BDI-II scores at pre-treatment to have greater treatment gains. This finding is in line with the findings of Schindler, Hiller and Witthöft [56]. However, Organista, Munoz and Gonzalez [57], Merrill et al. [26], and Teri and Lewinsohn [50] reported that lower initial BDI scores predicted greater improvement. Surprisingly, treatment response was not predicted by the length of treatment, suggesting that a time frame of 12 sessions may be sufficient.

The dropout rate (17.5\%) for patients in the present study was somewhat lower than the rates found in both the Hans and Hiller [49] meta-analysis (24.6\%) and the Neimeyer et al. [51] and Peeters et al. [54] studies (23.9\% and $28 \%$, respectively); however it was higher than in other investigations, e.g. the Teri and Lewinsohn [50] study (8\%). Age, sex, diagnosis, and BDI-II or BAI pre-treatment scores did not predict patient dropout. These results are consistent with previous findings [58,59]. As in the Arnow et al. study [59], there was a statistically non-significant tendency for dropouts to be younger in age.

Unfortunately, in the current investigation, there were only a few variables available to examine as predictors of dropout and treatment response. Other factors that have previously shown predictive value for outcomes in the treatment for depression (e.g., chronicity of problems [55], normal personality traits [60], personality disorders [61], intelligence [55], or attachment style [62]) should, if possible, be included in future effectiveness studies.

As encouraging as the results demonstrating the effectiveness of group CBT for depression - delivered in a specialized routine care setting, mainly by psychiatric nurses - are, too many patients drop out of treatment or do not benefit from treatment. There is a need to improve the treatment of these groups of patients. Because many clinicians overestimate the impact of their interventions [63], monitoring treatment outcomes and providing feedback to therapists may increase the effectiveness of treatment [64]. Systematic assessment of patients' suitability for this type of treatment may also contribute to higher response rates [65]. Finally, a combination of traditional CBT techniques and newer approaches to CBT (e.g., mindfulness-based CBT [66] or meta-cognitive therapy [67]) may enhance treatment effects.

The strengths of the present study are that a follow-up was included, diagnoses were established using a structured diagnostic interview, and appropriate statistical methods were used. On the other hand, effectiveness research faces challenges and involves limitations that also apply to the present study [27]. Because there was no control group, the observed effects cannot be attributed to the treatment with certainty and may instead be attributed to the passage of 
time or regression to the mean. No data were collected after patients dropped out of treatment; therefore, intentto-treat analyses could not be performed. The retrospective design of the current study poses additional problems and may be subject to potential biases. Only information already contained in patient records could be used. There was a high number of missing data points, and the quality of the patient records varied greatly. The exact reasons why data were lost are unknown. The missing data could have been due to clinicians not delivering the instruments to the patients or their failure to record patient results in their electronic record; alternatively, the patients may not have returned the inventories. There is a possibility that therapists may have chosen to not give the inventories to non-responders, which would bias the results. However, the results of Little's MCAR test suggest that the data were missing at random. Some demographic characteristics (e.g., marital status) were difficult to collect. More importantly, the information on the patients' use of medication, which was usually prescribed by the patient's general practitioner, was often inadequate, especially in the first years of the study period. It was therefore impossible to control for use of medication in the analyses, and the possibility that the observed changes in patient outcomes are due to the start of or a change in medication cannot be ruled out. However, in our experience, medication is rarely started or changed during group treatment. As is common in clinical practice, patients were selected for group treatment. Unfortunately, there were no available data for patients who were not offered group treatment or who dropped out before the start of group treatment. Thus, any possible selection bias could not be estimated. To overcome the problems inherent to a retrospective approach, we recommend a prospective design for future studies examining the effectiveness of psychotherapy in ordinary clinical settings. Such future studies could, for example, be conducted in conjunction with routine outcome monitoring [68]. Further, a shortcoming of the present study is that two different versions of the BDI were used. In addition, a follow-up period of three months is too short to make conclusions about the long-term effect of the treatment. Finally, in this study, only symptom reduction was measured; however, gains in well-being and life functioning should also be part of treatment evaluation [69] in future studies.

\section{Conclusion}

In conclusion, the present study demonstrates that group CBT for depression, delivered in routine care settings, has good results in terms of both improvement at the group level and clinical significance at the individual level. However, there are still many patients who drop out of treatment or who do not benefit from treatment.

\section{Additional file}

Additional file 1: Parts and timing plot.

Competing interests

The authors declare that they have no competing interests.

Authors' contributions

LA initiated the study, collected data, and helped to draft the manuscript. JCT performed the statistical analyses and drafted the manuscript. Both authors read and approved the final manuscript.

\section{Acknowledgements}

The authors want to thank the clinicians at the group treatment unit who provided the treatment and gave valuable comments on the project: Lesley Ann Smith, Ranveig Ersdal, Stein Feragen, Ørjan Svenøy, Wenche Nordnes, Sylva Krogh, and Trine Drage. The study was supported by research funds from the Helgeland Hospital Trust (to LA). The funding body had no influence on the study design, collection, analysis, and interpretation of data, the writing of the manuscript, and the decision to submit the manuscript for publication.

Received: 30 May 2014 Accepted: 10 October 2014

Published online: 21 October 2014

\section{References}

1. Butler AC, Chapman JE, Forman EM, Beck AT: The empirical status of cognitive-behavioral therapy: a review of meta-analyses. Clin Psychol Rev 2006, 26:17-31.

2. Cuijpers P, Andersson G, Donker T, van Straten A: Psychological treatment of depression: results of a series of meta-analyses. Nord J Psychiatry 2011, 65:354-364.

3. Hofmann SG, Asnaani A, Vonk IJ, Sawyer AT, Fang A: The efficacy of cognitive behavioral therapy: a review of meta-analyses. Cogn Ther Res 2012, 36:427-440

4. National Institute for Health and Care Excellence: Depression in adults. (CG90). London: National Institute for Health and Care Excellence; 2009.

5. Tucker M, Oei TPS: Is group more cost effective than individual cognitive behaviour therapy? The evidence is not solid yet. Behav Cogn Psychother 2007, 35:77-91.

6. Vos T, Corry J, Haby MM, Carter R, Andrews G: Cost-effectiveness of cognitive-behavioural therapy and drug interventions for major depression. Aust N Z J Psychiatry 2005, 39:683-692.

7. Morrison N: Group cognitive therapy: treatment of choice or suboptimal option? Behav Cogn Psychother 2001, 29:311-332.

8. Whitfield G: Group cognitive-behavioural therapy for anxiety and depression. Adv Psychiatr Treat 2010, 16:219-227.

9. McDermut W, Miller IW, Brown RA: The efficacy of group psychotherapy for depression: a meta-analysis and review of the empirical research. Clin Psychol-Sci Pract 2001, 8:98-116.

10. Oei TPS, Dingle G: The effectiveness of group cognitive behaviour therapy for unipolar depressive disorders. J Affect Disord 2008, 107:5-21.

11. Wampold BE, Minami T, Baskin TW, Callen Tierney S: A meta-(re)analysis of the effects of cognitive therapy versus 'other therapies' for depression. $J$ Affect Disord 2002, 68:159-165.

12. Huntley AL, Araya R, Salisbury C: Group psychological therapies for depression in the community: systematic review and meta-analysis. $\mathrm{Br} J$ Psychiatry 2012, 200:184-190.

13. Cuijpers $P$, van Straten A, Warmerdam L: Are individual and group treatments equally effective in the treatment of depression in adults? A meta-analysis. Eur J Psychiatry 2008, 22:38-51.

14. Okumura $Y$, Ichikura K: Efficacy and acceptability of group cognitive behavioral therapy for depression: a systematic review and meta-analysis. J Affect Disord 2014, 164:155-164.

15. Roth A, Fonagy P: What works for whom: A critical review of psychotherapy research. 2nd edition. New York: Guilford; 2005.

16. Zwarenstein M, Treweek S, Gagnier JJ, Altman DG, Tunis S, Haynes B, Oxman AD, Moher D: Improving the reporting of pragmatic trials: an extension of the CONSORT statement. BMJ 2008, 337:a2390. 
17. Garfield SL: Some problems associated with "validated" forms of psychotherapy. Clin Psychol: Sci Pract 1996, 3:218-229.

18. Westen $D$, Morrison K: A multidimensional meta analysis of treatments for depression, panic, and generalized anxiety disorder: an empirical examination of the status of empirically supported therapies. $J$ Consult Clin Psychol 2001, 69:875-899.

19. Westen D, Novotny CA, Thompson-Brenner H: The empirical status of empirically supported psychotherapies: assumptions, findings, and reporting in controlled clinical trials. Psychol Bull 2004, 130:631-663.

20. Zimmerman M, Chelminski I, Posternak MA: Generalizability of antidepressant efficacy trials: differences between depressed psychiatric outpatients who would or would not qualify for an efficacy trial. Am J Psychiatry 2005, 162:1370-1372.

21. Schindler AC, Hiller W, Witthoft M: Benchmarking of cognitive-behavioral therapy for depression in efficacy and effectiveness studies: how do exclusion criteria affect treatment outcome? Psychother Res 2011, 21:644-657.

22. Stirman SW, DeRubeis RJ, Crits-Christoph P, Rothman A: Can the randomized controlled trial literature generalize to nonrandomized patients? J Consult Clin Psychol 2005, 73:127-135

23. van der Lem $R$, de Wever WWH, van der Wee NJA, van Veen T, Cuijpers $P$, Zitman FG: The generalizability of psychotherapy efficacy trials in major depressive disorder: an analysis of the influence of patient selection in efficacy trials on symptom outcome in daily practice. BMC Psychiatry 2012, 12:192.

24. Hans E, Hiller W: Effectiveness of and dropout from outpatient cognitive behavioral therapy for adult unipolar depression: a meta-analysis of nonrandomized effectiveness studies. J Consult Clin Psychol 2013, 81:75-88.

25. Cuijpers P, van Straten A, Bohlmeijer E, Hollon SD, Andersson G: The effects of psychotherapy for adult depression are overestimated: a meta-analysis of study quality and effect size. Psychol Med 2010, 40:211-223.

26. Merrill KA, Tolbert VE, Wade WA: Effectiveness of cognitive therapy for depression in a community mental health center: a benchmarking study. J Consult Clin Psychol 2003, 71:404.

27. Westbrook D, Kirk J: The clinical effectiveness of cognitive behaviour therapy: outcome for a large sample of adults treated in routine practice. Behav Res Ther 2005, 43:1243-1261.

28. Shadish WR, Matt GE, Navarro AM, Siegle G, Crits-Christoph P, Hazelrigg MD, Jorm AF, Lyons LC, Nietzel MT, Prout HT, Robinson L, Smith ML, Svartberg M, Weiss B: Evidence that therapy works in clinically representative conditions. J Consult Clin Psychol 1997, 65:355-365.

29. Shadish WR, Navarro AM, Matt GE, Phillips G: The effects of psychological therapies under clinically representative conditions: a meta-analysis. Psychol Bull 2000, 126:512-529.

30. Beck AT, Rush AJ, Shaw BF, Emery G: Cognitive therapy of depression. New York: Guilford; 1979

31. Beck AT, Steer RA, Brown GK: Manual for the Beck Depression Inventory-II. San Antonio, TX: Psychological Corporation; 1996.

32. Dahl AA, Kruger MB, Dahl NH, Karlsson H, Von Knorring L, Stordal E: SPIFA: a presentation of the Structured Psychiatric Interview for General Practice. Nord J Psychiatry 2009, 63:443-453.

33. Sheehan DV, Lecrubier $Y$, Sheehan $\mathrm{KH}$, Amorim $\mathrm{P}$, Janavs J, Weiller $\mathrm{E}$ Hergueta T, Baker R, Dunbar GC: The Mini-International Neuropsychiatric Interview (M.I.N.I.): the development and validation of a structured diagnostic psychiatric interview for DSM-IV and ICD-10. J Clin Psychiatry 1998, 59:22-33.

34. Hagen R, Gråwe RW: Mestring av depresjon: manual. Trondheim: Tapir akademisk forl; 2006.

35. Aasen $\mathrm{H}$ : An empirical investigation of depression symptoms: norms, psychometric characteristics and factor structure of the Beck Depression Inventory-II. Main thesis. Bergen: University of Bergen, Department of Psychology; 2001.

36. Beck AT, Brown G, Epstein N, Steer RA: An inventory for measuring clinical anxiety - psychometric properties. J Consult Clin Psychol 1988, 56:893-897.

37. Nordhagen T: Beck Anxiety Inventory: translation and validation of a Norwegian version. Main thesis. Bergen: University of Bergen, Department of Psychology; 2001.

38. Gueorguieva R, Krystal JH: Move over anova: progress in analyzing repeated-measures data and its reflection in papers published in the Archives of General Psychiatry. Arch Gen Psychiatry 2004, 61:310-317.
39. West BT: Analyzing longitudinal data with the linear mixed models procedure in SPSS. Eval Health Prof 2009, 32:207-228.

40. Schlomer GL, Bauman S, Card NA: Best practices for missing data management in counseling psychology. J Couns Psychol 2010, 57:1-10

41. Sterne JAC, White IR, Carlin JB, Spratt M, Royston P, Kenward MG, Wood AM Carpenter JR: Multiple imputation for missing data in epidemiological and clinical research: potential and pitfalls. BMJ 2009, 339:157-160.

42. Little RJA: A test of missing completely at random for multivariate data with missing values. J Am Stat Assoc 1988, 83:1198-1202.

43. Schafer JL, Graham JW: Missing data: our view of the state of the art. Psychol Methods 2002, 7:147.

44. IBM: IBM SPSS Missing Values 20. New York: IBM Cooperation; 2011

45. Jacobson NS, Truax P: Clinical significance: a statistical approach to defining meaningful change in psychotherapy research. J Consult Clin Psychol 1991, 59:12-19.

46. Bauer S, Lambert MJ, Nielsen SL: Clinical significance methods: a comparison of statistical techniques. J Pers Assess 2004, 82:60-70.

47. Seggar LB, Lambert MJ, Hansen NB: Assessing clinical significance: application to the Beck Depression Inventory. Behav Ther 2002, 33:253-269.

48. Cohen J: Statistical power analysis for the behavioral sciences. Hillsdale, N. J.: Laurence Erlbaum; 1988.

49. Hiller W, Schindler AC, Lambert MJ: Defining response and remission in psychotherapy research: a comparison of the $\mathrm{RCl}$ and the method of percent improvement. Psychother Res 2012, 22:1-11.

50. Teri L, Lewinsohn PM: Individual and group treatment of unipolar depression: comparison of treatment outcome and identification of predictors of successful treatment outcome. Behav Ther 1986, 17:215-228.

51. Neimeyer RA, Kazantzis N, Kassler DM, Baker KD, Fletcher R: Group cognitive behavioural therapy for depression outcomes predicted by willingness to engage in homework, compliance with homework, and cognitive restructuring skill acquisition. Cogn Behav Ther 2008, 37:199-215.

52. van der Lem R, van der Wee NJA, van Veen T, Zitman FG: Efficacy versus effectiveness: a direct comparison of the outcome of treatment for mild to moderate depression in randomized controlled trials and daily practice. Psychother Psychosom 2012, 81:226-234.

53. Keitner Gl, Ryan CE, Solomon DA: Realistic expectations and a disease management model for depressed patients with persistent symptoms. J Clin Psychiatry 2006, 67:1412-1421.

54. Peeters F, Huibers M, Roelofs J, van Breukelen G, Hollon SD, Markowitz JC, van Os J, Arntz A: The clinical effectiveness of evidence-based interventions for depression: a pragmatic trial in routine practice. J Affect Disord 2013, 145:349-355.

55. Fournier JC, DeRubeis RJ, Shelton RC, Hollon SD, Amsterdam JD, Gallop R: Prediction of response to medication and cognitive therapy in the treatment of moderate to severe depression. J Consult Clin Psychol 2009, 77:775.

56. Schindler A, Hiller W, Witthöft M: What predicts outcome, response, and drop-out in CBT of depressive Adults? A naturalistic Study. Behav Cogn Psychother 2013, 41:365-370.

57. Organista KC, Muñoz RF, González G: Cognitive-behavioral therapy for depression in low-income and minority medical outpatients: description of a program and exploratory analyses. Cogn Ther Res 1994, 18:241-259.

58. Oei TP, Kazmierczak T: Factors associated with dropout in a group cognitive behaviour therapy for mood disorders. Behav Res Ther 1997, 35:1025-1030

59. Arnow BA, Blasey C, Manber R, Constantino MJ, Markowitz JC, Klein DN, Thase ME, Kocsis JH, Rush AJ: Dropouts versus completers among chronically depressed outpatients. J Affect Disord 2007, 97:197-202.

60. Bagby RM, Quilty LC, Segal ZV, McBride CC, Kennedy SH, Costa PT Jr: Personality and differential treatment response in major depression: a randomized controlled trial comparing cognitive-behavioural therapy and pharmacotherapy. Can J Psychiatry Revue Can de Psychiatr 2008, 53:361.

61. Newton-Howes G, Tyrer P, Johnson T, Mulder R, Kool S, Dekker J, Schoevers R: Influence of personality on the outcome of treatment in depression: systematic review and meta-analysis. J Pers Disord in press

62. Reis S, Grenyer BF: Fearful attachment, working alliance and treatment response for individuals with major depression. Clin Psychol Psychother 2004, 11:414-424.

63. Walfish S, McAlister B, O'Donnell P, Lambert MJ: An investigation of self-assessment bias in mental health providers. Psychol Rep 2012, 110:639-644. 
64. Knaup C, Koesters M, Schoefer D, Becker T, Puschner B: Effect of feedback of treatment outcome in specialist mental healthcare: meta-analysis. $\mathrm{Br} J$ Psychiatry 2009, 195:15-22.

65. Renaud J, Russell JJ, Myhr G: Predicting who benefits most from cognitive-behavioral therapy for anxiety and depression. J Clin Psychol in press

66. Segal ZV, Williams M, Teasdale JD, Kabat-Zinn J: Mindfulness-based cognitive therapy for depression. New York: Guilford Press; 2013

67. Wells A: Metacognitive therapy for anxiety and depression. New York: Guilford Press; 2009

68. Lambert M: Presidential address: what we have learned from a decade of research aimed at improving psychotherapy outcome in routine care. Psychother Res 2007, 17:1-14.

69. Howard KI, Lueger RJ, Maling MS, Martinovich Z: A phase model of psychotherapy outcome: causal mediation of change. J Consult Clin Psychol 1993, 61:678-685.

doi:10.1186/s12888-014-0292--

Cite this article as: Thimm and Antonsen: Effectiveness of cognitive behavioral group therapy for depression in routine practice. BMC Psychiatry 2014 14:292.

\section{Submit your next manuscript to BioMed Central and take full advantage of:}

- Convenient online submission

- Thorough peer review

- No space constraints or color figure charges

- Immediate publication on acceptance

- Inclusion in PubMed, CAS, Scopus and Google Scholar

- Research which is freely available for redistribution 